\title{
Lack of HIV RNA test result is a barrier to breastfeeding among women living with HIV in Botswana
}

\author{
Gloria Katuta Mayondi ${ }^{1 *}$ D, Aamirah Mussa ${ }^{1}$, Rebecca Zash ${ }^{1,2,3}$, Sikhulile Moyo ${ }^{1,2}$, Arielle Issacson 1,4, \\ Modiegi Diseko1', Judith Mabuta', Goabaone Mogomotsi ${ }^{5}$, Eldah Dintwa ${ }^{5}$, Joseph Makhema ${ }^{1,2}$, \\ Mompati Mmalane ${ }^{1}$, Shahin Lockman ${ }^{1,2,6}$, Chelsea Morroni ${ }^{1,7}$ and Roger Shapiro ${ }^{1,2,3}$
}

\begin{abstract}
Background: Botswana updated its antiretroviral treatment (ART) guidelines in May 2016 to support breastfeeding for women living with HIV (WLHIV) on ART who have documented HIV RNA suppression during pregnancy.

Methods: From September 2016 to March 2019, we evaluated feeding method at discharge among WLHIV at eight government maternity wards in Botswana within the Tsepamo Study. We validated the recorded feeding method on the obstetric record using the prevention of mother-to-child transmission of HIV (PMTCT) counsellor report, infant formula dispensing log or through direct observation. Available HIV RNA results were recorded from the obstetric record, and from outpatient HIV records (starting February 2018). In a subset of participants, we used electronic laboratory records to verify whether an HIV RNA test had occurred. Univariable and multivariable logistic regression analyses were performed to identify factors associated with infant feeding choice.
\end{abstract}

Results: Among 13,354 WLHIV who had a validated feeding method at discharge, 5303 (39.7\%) chose to breastfeed and 8051 (60.3\%) chose to formula feed. Women who had a documented HIV RNA result in the obstetric record available to healthcare providers at delivery were more likely to breastfeed (50.8\%) compared to women who did not have a documented HIV RNA result (35.4\%) (aOR 0.59; $95 \% \mathrm{Cl} 0.54,0.65)$. Among women with documented HIV RNA, 2711 (94.6\%) were virally suppressed $(<400$ copies $/ \mathrm{mL})$. Breastfeeding occurred in a substantial proportion of women who did not meet criteria, including 46 (30.1\%) of 153 women with HIV RNA > 400 copies $/ \mathrm{mL}$, and 134 (27.4\%) of 489 women with no reported ART use. A sub-analysis of electronic laboratory records among 150 women without a recorded result on the obstetric record revealed that 93 (62\%) women had an HIV RNA test during pregnancy.

Conclusions: In a setting of long-standing use of suppressive ART, with majority of WLHIV on ART from the time of conception, requiring documentation of HIV RNA suppression in the obstetric record to inform infant feeding decisions is a barrier to breastfeeding but unlikely to prevent a substantial amount of HIV transmission.

Keywords: HIV, Infant feeding, Women living with HIV, Breastfeeding, Viral load, Botswana

\footnotetext{
* Correspondence: gloria.mayondi@gmail.com

1 Botswana-Harvard AIDS Institute Partnership, Gaborone, Botswana

Full list of author information is available at the end of the article
}

(c) The Author(s). 2021 Open Access This article is licensed under a Creative Commons Attribution 4.0 International License, which permits use, sharing, adaptation, distribution and reproduction in any medium or format, as long as you give appropriate credit to the original author(s) and the source, provide a link to the Creative Commons licence, and indicate if changes were made. The images or other third party material in this article are included in the article's Creative Commons licence, unless indicated otherwise in a credit line to the material. If material is not included in the article's Creative Commons licence and your intended use is not permitted by statutory regulation or exceeds the permitted use, you will need to obtain permission directly from the copyright holder. To view a copy of this licence, visit http://creativecommons.org/licenses/by/4.0/. The Creative Commons Public Domain Dedication waiver (http://creativecommons.org/publicdomain/zero/1.0/) applies to the data made available in this article, unless otherwise stated in a credit line to the data. 


\section{Background}

Feeding method in the first 6 months of life plays an integral role in a child's health and development trajectory [1]. Breastfeeding is one of the foundations of child health and development and is associated with substantially lower child morbidity and mortality, including among HIV-exposed children [2, 3]. The 2010 and 2016 World Health Organization (WHO) guidelines on HIV and infant feeding define a primary goal of maximizing infant HIV-free survival [2-4] and support breastfeeding in the setting of maternal antiretroviral therapy (ART) or infant antiviral prophylaxis. In low-resource settings where diarrhoeal diseases, pneumonia and malnutrition are common causes of infant morbidity and mortality, WHO recommends exclusive breastfeeding for 6 months and continued breastfeeding up to 24 months with maternal or infant ARV protection in order to give infants the best chance for HIV-free survival [2, 5].

Despite outstanding ART coverage in pregnancy (95\%), with $64.5 \%$ of WLWHIV conceiving on ART and very low $(<1.5 \%)$ mother-to-child HIV transmission (MTCT) [6, 7], Botswana has been slow to adopt a policy of universal breastfeeding for HIV-exposed infants. With over $20 \%$ of infants in the country HIVexposed $[8,9]$ the lack of breastfeeding for these children contributes substantially to Botswana's high under-five mortality (41.6 deaths per 1000 live births) compared to the Sustainable Development Goal target to reduce under-five mortality to at least as low as 25 deaths per 1000 live births $[10,11]$. In recognition of this problem, Botswana chose to align its guidelines with those of the WHO in May 2016 to encourage greater breastfeeding for women living with HIV (WLHIV) on ART [12]. However, because Botswana can perform HIV RNA (viral load) testing as part of its ART program, the 2016 Botswana guidelines also specified that there should be documented HIV RNA suppression within the last 3 months of pregnancy to support a recommendation to breastfeed at the time of delivery. The updated guidelines also retain an individualised approach to feeding, recommending counselling during pregnancy to ensure each woman makes the best decision for her situation.

After decades of an MTCT prevention programme that relied on the use of formula, and with the additional requirement of documented viral suppression in the third trimester of pregnancy to support breastfeeding, it is currently unknown how the change in 2016 guidelines impacted actual feeding choices in Botswana. Therefore, we set out to describe feeding choices and potential barriers to breastfeeding among WLHIV in Botswana after the new guidelines were implemented.

\section{Methods}

\section{Study design and setting}

Tsepamo study overview

We performed an analysis of infant feeding and HIV RNA data collected in the Tsepamo Study, an ongoing non-interventional birth outcomes surveillance study that collects data from obstetric records at large public maternity wards throughout Botswana [13]. The primary study aims of Tsepamo are to evaluate adverse birth outcomes and congenital abnormalities by HIV status and ART regimen. The study occurs at geographically distributed sites in major population areas of Botswana (Fig. 1), where $>95 \%$ of women deliver in a healthcare facility. Although the study expanded from eight to 18 sites in 2018, only data from the original eight sites were included in this analysis; these sites were located in Gaborone and Francistown (tertiary referral centres) and Maun, Serowe, Selebi-Phikwe, Mahalapye, Molepolole and Ghanzi (district and primary-level hospitals).

\section{Data collection}

Data were abstracted from obstetric record cards into an electronic database by trained research assistants at the time of maternal discharge from the postnatal ward. The obstetric record card is a standardized government booklet to record the entirety of medical care during pregnancy and delivery, that is started at the first antenatal clinic (ANC) visit, and brought by the mother to each subsequent ANC visit and to the delivery site. Information extracted from the obstetric record included maternal demographic characteristics, medical history, medications prescribed at the time of conception and during pregnancy, maternal diagnoses during pregnancy, infant birth record, type of delivery, APGAR scores, gestational age, birthweight, congenital abnormalities, and vital status of the infant(s) at time of discharge. For WLHIV, the date of HIV diagnosis, most recent CD4 cell count, and antiretroviral history (including start date, regimen, and any switch or discontinuation during pregnancy) were also extracted. When available in the obstetric record, HIV RNA results were recorded. Births that occurred before arrival at the hospital and $<24$ weeks gestation were excluded.

For this analysis, we used data collected between September 2016 and March 2019 and women were included if they were living with HIV, if their baby was alive at the time of discharge, and if they had a validated feeding method recorded at discharge. Validation started in September 2016 and occurred through direct feeding observation or by checking the prevention of mother-tochild transmission of HIV (PMTCT) counsellor report or formula dispensing log.

All HIV RNA results documented in the obstetric record were abstracted. We verified a subset of randomly 


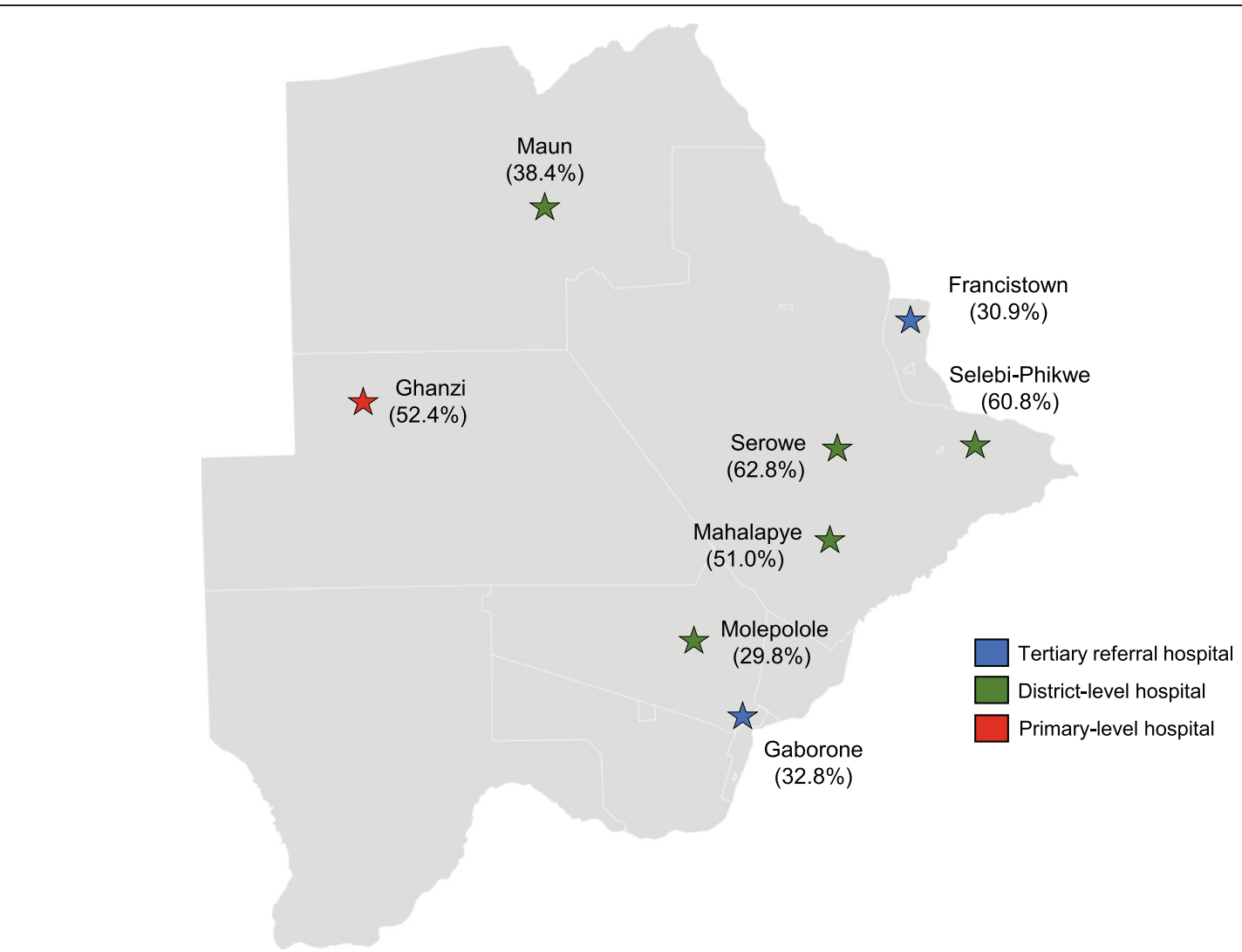

Fig. 1 Tsepamo study sites and percentage of WLHIV breastfeeding at discharge at each site

selected records from our sample (150 with and 150 without a documented HIV RNA result in the obstetric record) to determine whether an HIV RNA test had occurred during pregnancy. This verification was performed using the Integrated Patient Management System (IPMS), a nationwide electronic system that includes laboratory records. After February 2018, we also evaluated participants' Infectious Disease Control Centre (IDCC) cards (the medical record for outpatient HIV care), when available, to further identify HIV RNA results missing from the available obstetric record. However, it should be noted that the obstetric record was the only source of information routinely available through the Botswana PMTCT programme to help midwives in counselling for appropriate feeding recommendations at the time of delivery. While the IPMS captures laboratory records nationwide, not all maternity facilities have access to these electronic laboratory records. Laboratory results of participants are routinely sent nonelectronically to antenatal facilities for the nursing staff to transcribe them into participants' obstetric records.

\section{Statistical analysis}

Data were extracted from the electronic database in an excel format and analysed in Stata (Version 16,
StataCorp, College Station, Texas). Descriptive statistics were used to describe the infant feeding choices of WLHIV (proportions of women in each feeding group). To identify factors associated with infant feeding choices of WLHIV, we performed univariable and multivariable logistic regression analyses. Infant feeding choice was categorized as breastfeeding versus formula feeding where breastfeeding was used as the reference category in logistic regression models. All independent variables that were significant or nearly significant in univariable analysis $(P<0.1)$ were included in the multivariable model. Statistical significance was inferred at a $P$-value of $<0.05$. The outcome variable used was feeding choice at discharge. Independent variables of interest included age, marital status, education, occupation, nationality, delivery site, received antenatal care, documented viral load during pregnancy on the obstetric record, ART status during pregnancy, and gravida.

\section{Results}

Population and characteristics of the study sample

There were 63,044 total deliveries at the eight maternity sites between September 2016 and March 2019, with 14,851 (23.6\%) infants born to WLHIV. Of these WLHIV, 14,103 (95.0\%) had a baby that was discharged 
alive and 13,354 (94.7\%) of them had a validated feeding method recorded (Fig. 2). ART coverage was high, with 96.3\% of women in the study receiving ART during pregnancy: 8598 (64.8\%) started ART before conception and 4175 (31.5\%) initiated ART during pregnancy. Of those with a known ART start date, 12,200 (96.6\%) had received at least 8 weeks of ART before delivery. Table 1 shows the baseline characteristics of the study sample.

\section{Feeding choice and associated factors}

At discharge, 5303 (39.7\%) of the WLHIV with a validated feeding method were confirmed to be breastfeeding and 8051 (60.3\%) were formula feeding. The percentage of women breastfeeding increased by only $1.3 \%$ between $2016 / 2017$ to $2018 / 2019$.

In multivariable analysis, age, education, nationality, delivery site, attended antenatal visits, documentation of viral load during pregnancy and ART status during pregnancy (i.e., whether there was documentation of ART during pregnancy and whether ART was initiated prior to or during pregnancy) were associated with feeding choice (Table 2). Women aged 40 and older were the least likely to breastfeed, whereas those with a tertiary level of education or non-citizens of Botswana were more likely to breastfeed. Women who did not attend antenatal visits before delivery were less likely to breastfeed, as were women who delivered in a tertiary hospital (urban setting) rather than a primary/district hospital (rural or peri-urban setting). Women with no documentation of ART during pregnancy were less likely to be breastfeeding at discharge compared with women who either initiated ART before pregnancy or during pregnancy.

\section{Viral load availability}

HIV RNA availability was among the strongest predictors for breastfeeding in the multivariable analysis. Among the 13,354 women included, 11,161 had data on viral load documentation status, of which only 2865 (25.7\%) had a documented HIV RNA result available at delivery. Of these, 2711 (94.6\%) were virally suppressed $(<400$ copies $/ \mathrm{mL})$. Women who had a documented viral load during pregnancy were more likely to breastfeed compared with women that did not have a documented viral load (adjusted odds ratio (aOR) 0.59; 95\% CI 0.54, 0.65 ; $P$-value $<0.001)$. Among women with a documented viral load, $50.8 \%(n=1456)$ chose to breastfeed at discharge while only $35.4 \%(n=2936)$ of women without a documented viral load during pregnancy chose to breastfeed.

There were only $153(5.4 \%)$ women identified with HIV RNA $>400$ copies/mL in pregnancy, and of these, 46 (30.1\%) chose to breastfeed (contrary to Botswana guidelines). Likewise, breastfeeding was observed among 134 (27.4\%) of 489 women with no reported ART use in pregnancy (also contrary to the Botswana guidelines). We did note an increase in HIV RNA availability in the obstetric record over time, with $38.5 \%$ of participants having a documented viral load in 2018/2019 compared with $9.5 \%$ in $2016 / 2017$, representing a favourable trend.

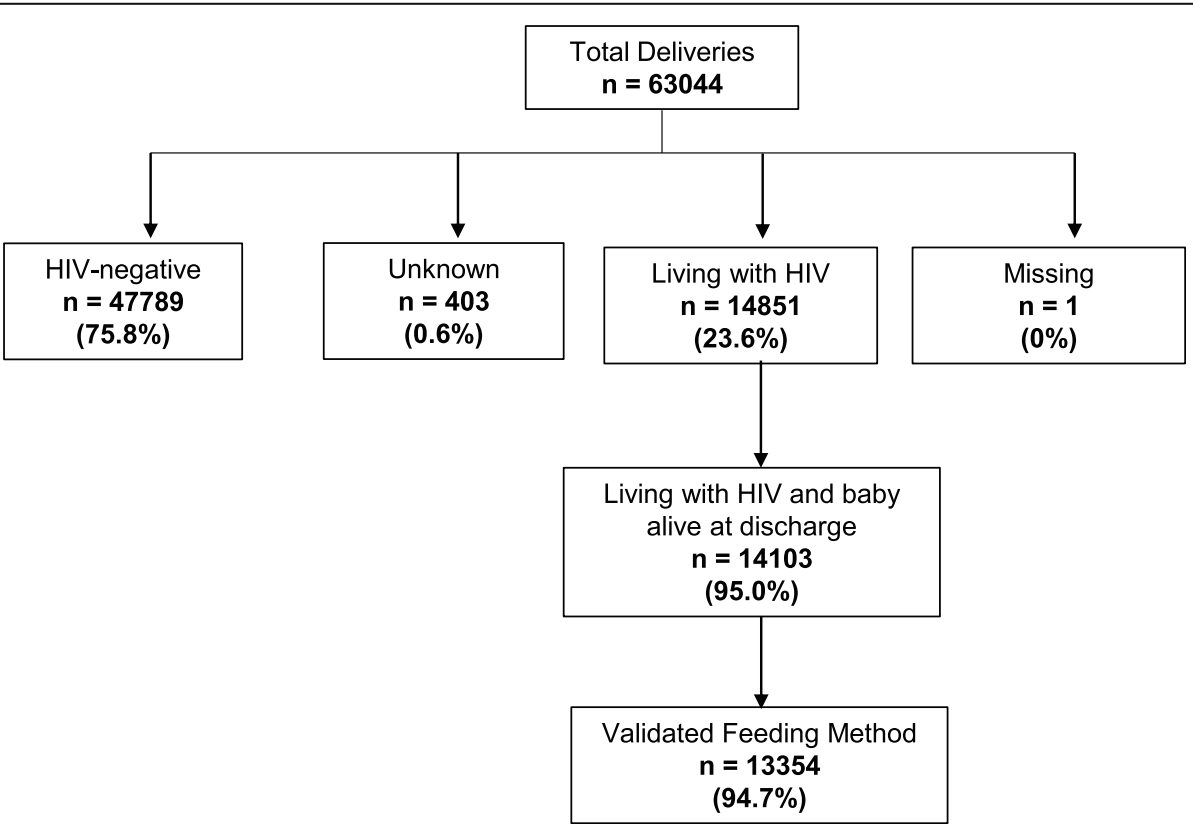

Fig. 2 Study population diagram 
Table 1 Characteristics of the study sample, by feeding status at discharge

\begin{tabular}{|c|c|c|c|}
\hline & $\begin{array}{l}\text { Total } \\
N(\%)\end{array}$ & $\begin{array}{l}\text { Breastfeeding at discharge } \\
n(\%)\end{array}$ & $\begin{array}{l}\text { Formula feeding } \\
\text { at discharge } \\
n(\%)\end{array}$ \\
\hline \multicolumn{4}{|l|}{ Age } \\
\hline Under 18 & $122(0.9)$ & $44(36.1)$ & $78(63.9)$ \\
\hline $18-29$ & $5460(40.9)$ & $2262(41.4)$ & 3198 (58.6) \\
\hline $30-39$ & $6722(50.4)$ & $2623(39.0)$ & 4099 (61.0) \\
\hline 40 and older & $1046(7.8)$ & $374(35.8)$ & $672(64.2)$ \\
\hline \multicolumn{4}{|l|}{ Marital Status } \\
\hline Single & $11,682(89.9)$ & 4624 (39.6) & $7058(60.4)$ \\
\hline Married & $1243(9.6)$ & $508(40.9)$ & $735(59.1)$ \\
\hline Widowed/divorced & $75(0.6)$ & $24(32.0)$ & $51(68.0)$ \\
\hline \multicolumn{4}{|l|}{ Education } \\
\hline Primary and below & $1539(11.7)$ & $622(40.4)$ & 917 (59.6) \\
\hline Secondary & 9957 (75.7) & $3894(39.1)$ & $6063(60.9)$ \\
\hline Tertiary & $1653(12.6)$ & $710(43.0)$ & $943(57.1)$ \\
\hline \multicolumn{4}{|l|}{ Occupation } \\
\hline Unemployed/student & $8133(63.2)$ & $3275(40.3)$ & $4858(59.7)$ \\
\hline Salaried employment & 4739 (36.8) & $1834(38.7)$ & $2905(61.3)$ \\
\hline \multicolumn{4}{|l|}{ Nationality } \\
\hline Motswana & $12,972(97.5)$ & 5137 (39.6) & $7835(60.4)$ \\
\hline Other & $337(2.5)$ & $156(46.3)$ & $181(53.7)$ \\
\hline \multicolumn{4}{|l|}{ Delivery Site } \\
\hline Primary/district hospitals & $6892(51.6)$ & $3247(47.1)$ & $3645(52.9)$ \\
\hline Tertiary hospitals & $6462(48.4)$ & $2056(31.8)$ & $4406(68.2)$ \\
\hline \multicolumn{4}{|l|}{ Attended antenatal visits } \\
\hline No & $383(2.9)$ & $102(26.6)$ & $281(73.4)$ \\
\hline Yes & $12,943(97.1)$ & $5188(40.1)$ & 7755 (59.9) \\
\hline \multicolumn{4}{|c|}{ Documentation of viral load during pregnancy } \\
\hline Yes & $2865(25.7)$ & $1456(50.8)$ & $1409(49.2)$ \\
\hline No & $8296(74.3)$ & $2936(35.4)$ & $5360(64.6)$ \\
\hline \multicolumn{4}{|l|}{ ART status during pregnancy } \\
\hline No documentation of ART in pregnancy & $489(3.7)$ & $134(27.4)$ & $355(72.6)$ \\
\hline ART initiated prior to pregnancy & $8598(64.8)$ & $3360(39.1)$ & $5238(60.9)$ \\
\hline ART initiated during pregnancy & $4175(31.5)$ & $1778(42.6)$ & $2397(57.4)$ \\
\hline \multicolumn{4}{|l|}{ Gravida } \\
\hline Primigravida & $1953(14.7)$ & $840(43.0)$ & $1113(57.0)$ \\
\hline Multigravida & $11,370(85.3)$ & $4454(39.2)$ & $6916(60.8)$ \\
\hline
\end{tabular}

\section{Electronic laboratory record verification}

We separately evaluated electronic national laboratory records for 150 women who had documentation of HIV RNA in pregnancy and 150 women who did not. Of these, 140 (93.3\%) with a documented HIV RNA result on the obstetric record had confirmation of that test in the laboratory database. For women with no documented HIV RNA result in the obstetric record, 93 (62.0\%) women had an HIV RNA test conducted during pregnancy, according to the laboratory database. This finding indicates that the lack of available viral load results at the time of discharge from the maternity ward was likely a combination of incomplete testing in pregnancy and incomplete recording of test results onto the obstetric record. 
Table 2 Univariable and multivariable analysis of characteristics associated with lack of breastfeeding among WLHIV in the Tsepamo Study

\begin{tabular}{|c|c|c|c|c|c|}
\hline & Total & OR $(95 \% \mathrm{Cl})$ & $P$-value & aOR $(95 \% \mathrm{Cl})$ & $P$-value \\
\hline Age & 13,350 & & & & \\
\hline Under 18 & 122 & $1.13(0.78,1.65)$ & 0.507 & $1.02(0.64,1.63)$ & 0.942 \\
\hline $18-29$ & 5460 & $0.90(0.84,0.97)$ & 0.007 & $0.94(0.86,1.04)$ & 0.224 \\
\hline $30-39$ & 6722 & Ref & Ref & Ref & Ref \\
\hline 40 and older & 1046 & $1.15(1.00,1.32)$ & 0.044 & $1.17(1.00,1.35)$ & 0.043 \\
\hline Marital Status & 13,000 & & & & \\
\hline Single & 11,682 & Ref & Ref & - & - \\
\hline Married & 1243 & $0.95(0.84,1.07)$ & 0.378 & - & - \\
\hline Widowed/divorced & 75 & $1.39(0.86,2.26)$ & 0.183 & - & - \\
\hline Education & 13,149 & & & & \\
\hline Primary and below & 1539 & $0.95(0.85,1.06)$ & 0.328 & $0.98(0.86,1.11)$ & 0.739 \\
\hline Secondary & 9957 & Ref & Ref & Ref & Ref \\
\hline Tertiary & 1653 & $0.85(0.77,0.95)$ & 0.003 & $0.83(0.73,0.94)$ & 0.004 \\
\hline Occupation & 12,872 & & & & \\
\hline Unemployed/student & 8133 & Ref & Ref & Ref & Ref \\
\hline Salaried employment & 4739 & $1.07(0.99,1.15)$ & 0.08 & $0.98(0.90,1.07)$ & 0.672 \\
\hline Nationality & 13,309 & & & & \\
\hline Motswana & 12,972 & Ref & Ref & Ref & Ref \\
\hline Other & 337 & $0.76(0.61,0.95)$ & 0.014 & $0.43(0.33,0.57)$ & $<0.001$ \\
\hline Delivery Site & 13,354 & & & & \\
\hline Primary/district hospitals & 6892 & Ref & Ref & Ref & Ref \\
\hline Tertiary hospitals & 6462 & $1.91(1.78,2.05)$ & $<0.001$ & $1.92(1.77,2.08)$ & $<0.001$ \\
\hline Attended antenatal visits & 13,326 & & & & \\
\hline No & 383 & $1.84(1.47,2.32)$ & $<0.001$ & $1.64(1.20,2.23)$ & 0.002 \\
\hline Yes & 12,943 & Ref & Ref & Ref & Ref \\
\hline Documentation of viral load during pregnancy & 11,161 & & & & \\
\hline Yes & 2865 & $0.53(0.49,0.58)$ & $<0.001$ & $0.59(0.54,0.65)$ & $<0.001$ \\
\hline No & 8296 & Ref & Ref & Ref & Ref \\
\hline ART status during pregnancy & 13,262 & & & & \\
\hline No documentation of ART in pregnancy & 489 & $1.70(1.39,2.08)$ & $<0.001$ & $1.37(1.03,1.82)$ & 0.032 \\
\hline ART initiated prior to pregnancy & 8598 & Ref & Ref & Ref & Ref \\
\hline ART initiated during pregnancy & 4175 & $0.86(0.80,0.93)$ & $<0.001$ & $0.90(0.81,1.00)$ & 0.048 \\
\hline Gravida & 13,323 & & & & \\
\hline Primigravida & 1953 & $0.85(0.77,0.94)$ & 0.001 & $0.88(0.77,1.00)$ & 0.057 \\
\hline Multigravida & 11,370 & Ref & Ref & Ref & Ref \\
\hline
\end{tabular}

OR Odds ratio (from univariable analysis), aOR Adjusted odds ratio (from multivariable analysis)

\section{Discussion}

We evaluated maternal feeding choice among WLHIV and identified ongoing low levels of breastfeeding following the 2016 guideline change in Botswana, and evidence that the requirement for a suppressed HIV RNA result during pregnancy may be a barrier to breastfeeding. To our knowledge, this is the first published data on feeding choices in Botswana after the new guidelines were implemented and in the treat all' ART era.

Breastfeeding among WLHIV in Botswana was low overall despite the guideline shift in 2016, with only $39.7 \%$ of women breastfeeding upon discharge from the maternity ward and an increase in breastfeeding of only $1.3 \%$ from $2016 / 2017$ to $2018 / 2019$. While this level of breastfeeding is higher than previous reports from 
Botswana before 2016 where fewer than 20\% of WLHIV chose to breastfeed $[14,15]$, it is significantly lower than in other African settings where studies have reported choice to exclusively breastfeed by $80-90 \%$ of WLHIV $[16,17]$. Most African countries with the highest HIV prevalence have adopted a public health approach rather than an individualized approach to support breastfeeding for WLHIV [18, 19]. In 2011, Botswana's neighbouring country, South Africa, committed to promoting exclusive breastfeeding for WLHIV following the WHO 2010 guidelines on HIV and infant feeding and ended the universal formula programme for WLHIV. In contrast, Botswana continues to provide infant formula free-ofcharge for all WLHIV who choose to formula feed.

Our hypothesis that the requirement for documented HIV RNA suppression in pregnancy served as a barrier to breastfeeding was confirmed. Only $25.7 \%$ of women had an HIV RNA (viral load) result documented in the obstetric record overall, and the presence of a result (95\% of which were virally suppressed) did correlate with the choice to breastfeed. This low availability was only partially reflective of actual HIV RNA testing in pregnancy, as our electronic record verification identified that $62 \%$ of women with no documented HIV RNA result on the obstetric record did have an HIV RNA test performed during pregnancy. Thus, one implication of our findings is that improved documentation of HIV RNA results in the obstetric record (or improved access of maternity nurses to the electronic records) could improve breastfeeding uptake. However, we also noted an increase in available HIV RNA results over time that was larger than the increase in breastfeeding, suggesting that other factors may have also played a role in the reluctance to choose to breastfeed. Feeding decisions may have been influenced by earlier guidance in Botswana which emphasized formula feeding, fear of MTCT [20], ambiguous/confusing messages regarding infant feeding $[20,21]$ and lack of social supports for breastfeeding among WLHIV [22]. In addition, while most HIV RNA results were undetectable $(<400$ copies $/ \mathrm{mL})$, some women without a result or with unsuppressed HIV RNA still chose to breastfeed, indicating that factors beyond MTCT risk were likely involved in feeding decisions.

We identified additional factors associated with lack of breastfeeding in our multivariable analysis, most of which were consistent with prior studies [20, 23]. Lack of prior antenatal visits was a strong risk factor, which may have been related to lack of a possible HIV RNA result in pregnancy or differences in counselling practices for these women. Women who delivered in a tertiary hospital were less likely to breastfeed compared with women who delivered in a primary/district hospital, but it is not known whether this was related to differences in patient populations at these tertiary centres, counselling differences, or other factors associated with urban locations. We also found age, education, nationality, and ART status during pregnancy to be associated with feeding choice.

Our study had several limitations. We were only able to evaluate feeding method at the time of maternity ward discharge. The decision to breastfeed at the time of discharge from maternity does not equate with exclusive breastfeeding for the WHO recommended 6 months. A prospective study would be needed to examine breastfeeding patterns throughout infancy. While there is a high percentage of viral suppression in Botswana overall (85\%) [6], the 95\% suppression in this report may be artificially high if women who tested were those most motivated by PMTCT concerns. However, multiple prior studies in Botswana support this high level of suppression in pregnancy, and we believe this indicates a true low MTCT risk for most breastfeeding women [5, 14]. Strategies that evaluate time on ART and adherence to ART that can be performed by maternity nurses throughout ANC and at the time when infant feeding decisions occur may be a useful alternative to reliance on HIV RNA documentation.

\section{Conclusions}

Despite a guideline shift in 2016 designed to support breastfeeding among WLHIV, fewer than $40 \%$ of WLHIV in Botswana from 2016 to 2019 chose to breastfeed their infants. This low rate of breastfeeding underscores the need to address barriers affecting feeding choices, including the requirement for documented HIV RNA suppression. While additional barriers to breastfeeding exist and should be explored, in a setting of long-standing use of suppressive ART with almost twothirds of WLHIV conceiving on ART and high overall suppression, the requirement for documented HIV RNA suppression is unlikely to prevent a substantial amount of HIV transmission during breastfeeding but likely contributes to low rates of breastfeeding.

\section{Abbreviations}

ANC: Antenatal clinic; aOR: Adjusted odds ratio; ART: Antiretroviral therapy; Cl: Confidence interval; HIV: Human Immunodeficiency Virus; IDCC: Infectious disease control clinic; OR: Odds ratio; PMTCT: Prevention of mother-to-child transmission; RNA: Ribonucleic acid; WHO: World Health Organization; WLHIV: Women living with HIV

\footnotetext{
Acknowledgements

We wish to thank the mothers who participated in the Tsepamo study, the Botswana Ministry of Health, the participating hospitals and maternity ward nurses, the staff at the Botswana Harvard Partnership, and the Tsepamo research assistants: Cynthia Dube, Keemenao Mosala, Tsaone Gaonakala, Gosego Legase, Onkabetse Mokgosi, Rosemary Moremi, Shally Morgan, Edith Moseki, Tshephang Motlotlegi, Mmapula Ofhentse, Daphne Lekorwe, Kebabonye Rabasiako, Naledi Kamanga, Bathoba Mabiletsa, Nametsegang Tshosa, Annah Kgannyeng, Patricia Mophuthegi, Thabologo Baitsemi, Tshegofatso Sebetso, Tsholofelo Maswabi, Pricilla Mashona, Seele Mafokate, Kealeboga Mmokele, Obakeng Makalane and Masego Kgafela.
} 


\section{Authors' contributions}

GKM, RS and RZ conceptualized this analysis. GKM and AM analysed the data. GKM wrote the first draft of the paper which was revised by RS and AM contributed to subsequent drafts of the manuscript. SM contributed to data analysis and reviewed the manuscript. RZ, Al, MD, JM, GM, ED, JM, MM $S L$ and CM critically reviewed the manuscript. All authors have read and approved the final manuscript

\section{Funding}

The Tsepamo study is funded by the Eunice Kennedy Shriver National Institute of Child Health and Human Development (R01 HD080471, R01 HD095766), which also provides support to RZ K23 HD088230). The funder had no role in the design or conduct of the study; data collection, analysis, or reporting; or the decision to submit the manuscript for publication.

\section{Availability of data and materials}

Data are not publicly available but may be provided by the corresponding and senior authors upon reasonable request and with permission of the Institutional Review Boards which oversee the study.

\section{Declarations}

\section{Ethics approval and consent to participate}

The Tsepamo study is reviewed and approved by two Institutional Review Boards: the Health Research and Development Committee in Botswana (HRDC \# 00751) and the Harvard Longwood Campus IRB at the Harvard T. H. Chan School of Public Health (IRB \# 00002218). The data analysed and reported here were collected anonymously.

\section{Consent for publication}

Not applicable.

\section{Competing interests}

The authors declare no competing interests.

\section{Author details}

Botswana-Harvard AIDS Institute Partnership, Gaborone, Botswana. ${ }^{2}$ Department of Immunology and Infectious Diseases, Harvard T.H. Chan School of Public Health, Boston, MA, USA. ${ }^{3}$ Division of Infectious Diseases, Beth Israel Deaconess Medical Center, Boston, MA, USA. ${ }^{4}$ Harvard Medical School, Boston, MA, USA. ${ }^{5}$ Ministry of Health and Wellness, Gaborone, Botswana. 'Division of Infectious Disease, Brigham and Women's Hospital, Boston, MA, USA. ${ }^{7}$ MRC Centre for Reproductive Health, University of Edinburgh, Edinburgh, UK.

Received: 30 March 2021 Accepted: 21 September 2021 Published online: 13 October 2021

\section{References}

1. Nieuwoudt S, Manderson L. Frontline health workers and exclusive breastfeeding guidelines in an HIV endemic south African community: a qualitative exploration of policy translation. Int Breastfeed J. 2018;13(1):20. https://doi.org/10.1186/s13006-018-0164-y.

2. WHO and UNICEF. Guideline: updates on HIV and infant feeding: the duration of breastfeeding, and support from health services to improve feeding practices among mothers living with HIV. 2016 [cited 2020 Feb 11]. Available from: https://apps.who.int/iris/bitstream/handle/10665/246260/ 9789241549707-eng.pdf? sequence $=1$

3. Mallampati D, MacLean RL, Shapiro R, Dabis F, Engelsmann B, Freedberg KA, et al. Optimal breastfeeding durations for HIV-exposed infants: the impact of maternal ART use, infant mortality and replacement feeding risk. J Int AIDS Soc. 2018;21(4):e25107. https://doi.org/10.1002/jia2.25107.

4. WHO. Guidelines on HIV and infant feeding. 2010: Principles and recommendations for infant feeding in the context of HIV and a summary of evidence. 2010 [cited 2020 Feb 11]. Available from: https://apps.who.int/ iris/bitstream/handle/10665/44345/9789241599535_eng.pdf?sequence=1

5. Shapiro RL, Kitch D, Ogwu A, Hughes MD, Lockman S, Powis K, et al. HIV transmission and 24-month survival in a randomized trial of HAART to prevent MTCT during pregnancy and breastfeeding in Botswana. AIDS. 2013;27(12):1911-20. https://doi.org/10.1097/QAD.0b013e32836158b0.
6. Botswana Country Operational Plan: COP20 Strategic Direction Summary [Internet]. 2020. Available from: https://www.state.gov/wp-content/uploa ds/2020/07/COP-2020-Botswana-SDS-FINAL.pdf. Accessed 11 Nov 2020.

7. Gaolathe T, Wirth KE, Holme MP, Makhema J, Moyo S, Chakalisa U, et al. Botswana's progress toward achieving the 2020 UNAIDS 90-90-90 antiretroviral therapy and virological suppression goals: a population-based survey. Lancet HIV. 2016;3(5):e221-30. https://doi.org/10.1016/S2352-3018(1 6)00037-0.

8. Ajibola G, Leidner J, Mayondi GK, van Widenfelt E, Madidimalo T, Petlo C, et al. HIV exposure and formula feeding predict under-2 mortality in HIVuninfected children, Botswana. J Pediatr. 2018;203:68-75.e2.

9. Zash R, Souda S, Leidner J, Ribaudo H, Binda K, Moyo S, et al. HIV-exposed children account for more than half of 24-month mortality in Botswana. BMC Pediatr. 2016;16(1):103. https://doi.org/10.1186/s12887-016-0635-5.

10. UNICEF. Child survival and the SDGs. 2020 [cited 2020 Dec 4]. Available from: https://data.unicef.org/topic/child-survival/child-survival-sdgs/\#more-1 616

11. UNICEF. Key demographic indicators: Botswana. Available from: https://da ta.unicef.org/country/bwa/. Accessed 4 Dec 2020.

12. Botswana MoHW. Handbook of the Botswana 2016 Integrated HIV Clinical Care Guidelines. 2016 [cited 2020 Feb 11]. Available from: https://aidsfree. usaid.gov/sites/default/files/botswana_art_2016.pdf

13. Zash R, Jacobson DL, Diseko M, Mayondi G, Mmalane M, Essex M, et al. Comparative safety of antiretroviral treatment regimens in pregnancy. JAMA Pediatr. 2017;171(10):e172222. https://doi.org/10.1001/jamapediatrics.201 7.2222.

14. Lockman S, Hughes M, Powis K, Ajibola G, Bennett K, Moyo S, et al. Effect of co-trimoxazole on mortality in HIV-exposed but uninfected children in Botswana (the Mpepu study): a double-blind, randomised, placebocontrolled trial. Lancet Glob Heal. 2017;5(5):e491-500. https://doi.org/10.101 6/S2214-109X(17)30143-2.

15. Ndubuka J, Ndubuka N, Li Y, Marshall CM, Ehiri J. Knowledge, attitudes and practices regarding infant feeding among HIV-infected pregnant women in Gaborone, Botswana: a cross-sectional survey. BMJ Open. 2013;3(11): e003749. https://doi.org/10.1136/bmjopen-2013-003749.

16. Adeniyi OV, Ajayi Al, Issah M, Owolabi EO, Ter Goon D, Avramovic G, et al. Beyond health care providers' recommendations: understanding influences on infant feeding choices of women with HIV in the eastern cape, South Africa. Int Breastfeed J. 2019;14(1):7. https://doi.org/10.1186/s13006-019-02 01-5.

17. Gejo NG, Weldearegay HG, Wtinsaie KT, Mekango DE, Woldemichael ES, Buda AS, et al. Exclusive breastfeeding and associated factors among HIV positive mothers in Northern Ethiopia. PLoS One. 2019;14(1):e0210782. https://doi.org/10.1371/journal.pone.0210782.

18. South Africa Department of Health. The Tshwane declaration of support for breastfeeding in South Africa. S Afr J Clin Nutr. 2011;24:214.

19. Ministry of Health Kingdom of Swaziland. Swaziland Integrated HIV Management Guidelines. 2015 [cited 2020 Feb 10]. Available from: https://a idsfree.usaid.gov/sites/default/files/tx_swaziland_2015.pdf

20. Motswere-Chirwa C. Factors influencing infant feeding choices among mothers living with HIV in Francistown, Botswana. Thesis. Univ. West. Cape. 2018.

21. Keakabetse TR, Paul T, Moremi L, Seitio-Kgokgwe O, Tomeletso T, Stockton $R$, et al. Infant Feeding Patterns Of HIV Positive Mothers And Disclosure Of Status To Family And Partners In Botswana. J AIDS Clin Res STDs. 2019. https://doi.org/10.24966/ACRS-7370/100027.

22. Breastfeeding rates low - Somolekae [Internet]. Dly. News Botswana. 2014. Available from: http://www.dailynews.gov.bw/news-details.php?nid=13676. Accessed 4 Dec 2020

23. Nabwera HM, Jepkosgei J, Muraya KW, Hassan AS, Molyneux CS, Ali R, et al. What influences feeding decisions for HIV-exposed infants in rural Kenya? Int Breastfeed J. 2017;12(1):31. https://doi.org/10.1186/s13006-017-0125-x.

\section{Publisher's Note}

Springer Nature remains neutral with regard to jurisdictional claims in published maps and institutional affiliations. 